\title{
Comparison of Corticosteroids by 3 Approaches to the Treatment of Chronic Rhinosinusitis With Nasal Polyps
}

\section{OPEN ACCESS}

Received: Dec 20, 2018

Revised: Feb 8, 2019

Accepted: Feb 21, 2019

Correspondence to Luo Zhang, MD, PhD

Beijing Institute of Otolaryngology, No. 17, Hougou HuTtng, Dongcheng District,

Beijing 100005, China.

Tel: +86-10-65141136

Fax: +86-10-85115988

E-mail:dr.luozhang@139.com

Chengshuo Wang, MD, PhD

Department of Otolaryngology Head and Neck

Surgery, Beijing Tongren Hospital, Capital

Medical University, No.1, Dongjiaominxiang,

Dongcheng District, Beijing 100730, China.

Tel: +86-10-58268375

Fax: +86-10-85115988

E-mail:wangcs830@126.com

†Yunyun Zhang and Hongfei Lou contributed equally to this paper.

Copyright $\odot 2019$ The Korean Academy of Asthma, Allergy and Clinical Immunology . The Korean Academy of Pediatric Allergy and Respiratory Disease

This is an Open Access article distributed under the terms of the Creative Commons Attribution Non-Commercial License (https:// creativecommons.org/licenses/by-nc/4.0/) which permits unrestricted non-commercial use, distribution, and reproduction in any medium, provided the original work is properly cited.

\section{Yunyun Zhang, ${ }^{1,2+}$ Hongfei Lou $\mathbb{1}^{1,2+}$ Yang Wang, ${ }^{2}$ Ying Li, ${ }^{2}$ Luo Zhang $\mathbb{1},{ }^{1,2,3^{*}}$ Chengshuo Wang $\mathbb{1}^{1,2^{*}}$}

'Department of Otolaryngology Head and Neck Surgery, Beijing Tongren Hospital, Capital Medical University, Beijing, China

${ }^{2}$ Beijing Key Laboratory of Nasal Diseases, Beijing Institute of Otolaryngology, Beijing, China

${ }^{3}$ Department of Allergy, Beijing Tongren Hospital, Capital Medical University, Beijing, China

\section{ABSTRACT}

Purpose: Corticosteroids are regarded as the mainstay of medical treatment of eosinophilic chronic rhinosinusitis with nasal polyps (ECRSwNP). To date, a head-to-head comparison of the efficacy and safety of glucocorticoid preparations administered via different routes for the treatment of chronic rhinosinusitis with nasal polyps has not been reported. To compare the efficacy and safety of steroids administered via the oral, intranasal spray and transnasal nebulization routes in the management of ECRSwNP over a short course.

Methods: Overall, 91 patients with ECRSwNP were recruited prospectively and randomized to receive either oral methylprednisolone, budesonide inhalation suspension (BIS) via transnasal nebulization, or budesonide nasal spray (BNS) for 2 weeks. Nasal symptoms and polyp sizes were assessed before and after the treatment. Similarly, nasal polyp samples were evaluated for immunological and tissue remodeling markers. Serum cortisol levels were assessed as a safety outcome.

Results: Oral methylprednisolone and BIS decreased symptoms and polyp sizes to a significantly greater extent from baseline $(P<0.05)$ than BNS. Similarly, BIS and oral methylprednisolone significantly reduced eosinophils, T helper 2 cells, eosinophil cationic protein, interleukin (IL)-5, and expression of matrix metalloproteinases 2 and 9 , and significantly increased type 1 regulatory T cells, IL-10, transforming growth factor- $\beta$, and tissue inhibitor of metalloproteinases 1 and 2 in nasal polyps to a greater extent than BNS. Post-treatment serum cortisol levels were significantly decreased by oral methylprednisolone compared to BIS or BNS, which did not significantly alter the cortisol levels.

Conclusions: A short course of BIS transnasal nebulization is more efficacious compared to BNS in the management of ECRSwNP and is safer than oral methylprednisolone with respect to hypothalamic-pituitary-adrenal axis function.

Keywords: Chronic rhinosinusitis; glucocorticoids; nasal polyps; nasal spray; transnasal nebulization 
ORCID iDs

Hongfei Lou (iD)

https://orcid.org/0000-0002-8553-812X Luo Zhang (iD)

https://orcid.org/0000-0002-0910-9884

Chengshuo Wang (iD

https://orcid.org/0000-0003-0646-5135

Disclosure

There are no financial or other issues that

might lead to conflict of interest.

\section{INTRODUCTION}

Chronic rhinosinusitis with nasal polyps (CRSwNP) is a chronic inflammatory disease of the nasal and paranasal sinus mucosae, which affects about $8 \%$ of the general population in China. ${ }^{1}$ The 2012 European Position Paper on Rhinosinusitis and Nasal Polyps (EPOS 2012) ${ }^{2}$ supports the topical intranasal steroid spray to be a safe and effective treatment. ${ }^{3.5}$ Shortterm systemic steroids may reduce the need for surgery; however, there are concerns about possible side-effects ${ }^{6-8}$ with long-term use.

Besides nasal sprays and oral steroids, other forms of glucocorticoid preparations, such as budesonide inhalation suspension (BIS), have attracted increasing interest for the treatment of CRSwNP. Some studies have investigated the use of BIS (Pulmicort Respules, AstraZeneca) in saline irrigation to manage CRSwNP. ${ }^{911}$ Others have investigated the efficacy and safety of short- and long-term therapies with BIS delivered via a mucosal atomization device in patients with CRS and demonstrated that while BIS was safe and effective over a 60-day treatment period. ${ }^{12}$ Indeed, preliminary studies have also indicated that shortterm budesonide transnasal nebulization is a safe and effective treatment in patients with eosinophilic chronic rhinosinusitis with nasal polyps (ECRSwNP). ${ }^{13}$ To date, a head-to-head comparison of the efficacy and safety of the different forms of glucocorticoid preparations commonly employed for the treatment of CRSwNP has not been reported. The primary aim of this study therefore was to compare the efficacy and safety of BIS administered via transnasal nebulization with budesonide nasal spray (BNS) and oral steroids in the management of patients with ECRSwNP. The secondary aim was to explore the effects of the different treatments on immunological makers and tissue remodeling in ECRSwNP patients.

\section{MATERIALS AND METHODS}

\section{Patients}

Ninety-one patients were enrolled in the study from Beijing TongRen Hospital, Beijing PR China, during the period from September 2015 to December 2017. The diagnosis of ECRSwNP was based on the standard criteria issued in the European Position Paper on Rhinosinusitis and Nasal Polyps guidelines for CRSwNP ${ }^{2}$ and modified for ECRSwNP according to Lou and colleagues. ${ }^{14}$ All participants were outpatients at the otolaryngology clinic and were diagnosed by ear, nose and throat specialists as suffering from CRSwNP; based on the symptoms of rhinosinusitis (nasal obstruction, nasal discharge, loss of smell and headache/facial pain) for at least 12 weeks, and confirmed by computed tomography scanning for abnormalities in all sinuses. The presence of bilateral nasal polyps (NPs) was also confirmed by using nasal endoscopy and the incidence of ECRSwNP was confirmed by the presence of $>54 \%$ eosinophils of total infiltrating inflammatory cells in polyp tissue biopsies, as evaluated by hematoxylin and eosin (H\&E) staining. ${ }^{14}$

Exclusion criteria included oral corticosteroid treatment within the last 3 months, sinus surgery within the last year, aspirin intolerance, cystic fibrosis, pregnancy, serious/unstable concurrent disease or any psychological disorders.

\section{Study design}

This was a prospective, randomized, head-to-head study (clinical trial registration details are available from http://clinicaltrial.gov/show/NCT03687515). Patients were randomly assigned to 
3 treatment groups: group A received oral methylprednisolone $24 \mathrm{mg}$ once a day (QD), group B received $1 \mathrm{mg} / 2 \mathrm{~mL}$ Pulmicort Respules (BIS) twice daily, and group C received BNS $256 \mu \mathrm{g}$ BID. The choice of daily oral dose of prednisolone was calculated according to the guideline dose of prednisolone $0.5 \mathrm{mg} / \mathrm{kg}$; based on an average weight of $60 \mathrm{~kg}$ for each patient; with each patient receiving prednisolone $30 \mathrm{mg}$ QD equivalent to methylprednisolone $24 \mathrm{mg}$ QD as recommended by Scadding and colleagues. ${ }^{15}$ Similarly, the dosage of BIS was based on our previous studies, ${ }^{13}$ while that of BNS is the standard recommended dose use for CRSwNP. All treatments were administered for 2 weeks. Study medications in group B were administered by means of a Pari Sinus Nebulizer and Pari Sinus Compressor (PARI GmbH, Starnberg,Germany) with a nebulizer face mask directed to the nostrils. Prior to use, the patient was familiarized with and instructed on the correct use of the nebulizer by the investigator. The patient was asked to breathe normally and the BIS was inhaled through the nose using the face mask until the full study dose of BIS had been administered. Nebulization of the medication was generally well tolerated and completed over a period of 5 minutes for each dose.

The physician's assessment of reduction in NP size and the patient's assessment of improvements in symptoms were used as the primary clinical end points. Nasal symptoms (including nasal obstruction, rhinorrhea, loss of smell and headache/facial pain) were assessed using the visual analogue scale (VAS) both before initiation of treatment (which was scheduled 1 week after the screening biopsy was taken to confirm the presence of ECRSwNP) and at the end of the 14-day treatment period. Total nasal symptom score (TNSS) was calculated as the sum of 4 individual symptoms at the same time. Similarly, NPs sizes were measured by endoscopic examination at the commencement and the end of treatment. The effect of treatment on asthma control and fractional nitric oxide (FeNO) were also investigated as primary clinical outcomes.

Assessment of the effect of treatment on eosinophil numbers, several makers for inflammation, markers for nasal tissue remodeling in nasal biopsy tissues obtained before and after treatment were used as secondary outcome measures.

This study was approved by the Medical Ethics Committee of Beijing Tongren Hospital, and all patients provided informed signed consent before enrolment in the study.

\section{Efficacy assessment}

\section{Primary outcomes}

Patients assessed improvements in each of the 4 major symptoms by scoring on the VAS. Four major symptoms, including nasal obstruction, rhinorrhea, loss of smell and headache/ facial pain, were assessed by the patient using a VAS of 0 to 10; where 0 indicated the absence of any symptom and 10 signified the presence of the most severe nasal obstruction, nasal rhinorrhea, loss of smell and headache/facial pain. TNSS was calculated as the sum of all symptom scores for each patient.

Physicians assessed NP size reduction by endoscopic examination according to the Kennedy score. Polyp size was scored as 0 to 3 for each side and the bilateral polyp grade was obtained as the sum of the individual units for the left and right nasal cavities (max: 6). Polyp size was scored as $0=$ no polyps; $1=$ polyps in the middle meatus, not reaching below the inferior border of the middle turbinate; 2 = polyps reaching below the inferior border of the middle turbinate, but not below the inferior border of the inferior turbinate; and 3=large polyps reaching below the inferior turbinate. 
The effect of treatment on asthma control in individuals with comorbid asthma was measured by the improvement of forced expiratory volume in 1 second/forced vital capacity (FEV1/FVC). FeNO was measured in all participants by using a chemiluminescence analyser (NIOX; MINO 09-1000, Aerocrine AB, Sweden).

\section{Secondary outcomes}

All NP tissues were evaluated by means of H\&E staining to determine eosinophil infiltration. Samples from patients in 3 groups were evaluated in a blind fashion with respect to the pre- and post-treatment sequences. Data were not available for all subjects because of the relatively small sizes of the individual samples obtained. Thus, all NP tissues were evaluated by means of H\&E staining, and then samples from patients in each treatment group were randomly divided into approximately 3 equal subgroups. One set of the biopsies was processed according to standard histological procedures. Paraffin sections prepared from each biopsy tissue were stained with H\&E, and were then assessed by bright-field light microscopy at $\times 400$ magnification for intraepithelial eosinophil infiltration. The number of positive cells was counted and reported as the mean of the counts for at least 6 grids of $0.2 \mathrm{~mm}^{2}$ each.

Another set of biopsies was processed for the assessment of collagen content in the extracellular matrix by the picrosirius red staining technique as reported by Li et al. ${ }^{16}$ Briefly, paraffin sections were deparaffinized, hydrated and stained with picrosirius red for 60 minutes. The sections stained were washed in 2 changes of acidified water and were dehydrated in 3 changes of $100 \%$ ethanol before analysis by means of microscopy with an Olympus microscope (CX-40) equipped with filters to provide circularly polarized illumination. Tissue images were viewed under both bright-field and polarized light conditions at $\times 400$ magnification and recorded with a digital camera (Olympus BX-41). The total collagen content in each sample was assessed as the mean percentage of positively stained section in 10 randomly selected fields and collagen type 3 fibres present in the tissue were determined by using polarized light microscopy. Collagen content was calculated in the digital images taken under bright-field microscopy. The percentage of positively stained area was determined from 10 randomly selected fields per sample to analyze total collagen content and collagen type 3 fibres present in the tissue were determined by polarized light microscopy.

The third set of samples was processed for the assessment of inflammatory and tissue remodeling mediators by immunoassay. Samples to be assessed by immunoassay was weighed and mixed with a total of $1.0 \mathrm{~mL}$ of PBS supplemented with $0.05 \%$ Tween 20 (Sigma-Aldrich, St. Louis, MO, USA), and 1\% protease inhibitor cocktail (Sigma-Aldrich) was added for every $100 \mathrm{mg}$ of tissue. All samples were homogenized with a standard benchtop homogenizer (Polytron PT 2100, Kinematica, Switzerland) at 1,000 rpm for 5 minutes, and the homogenates were centrifuged at $1,500 \mathrm{~g}$ for 10 minutes at $4^{\circ} \mathrm{C}$. The supernatants were collected from each sample and were stored at $-80^{\circ} \mathrm{C}$ until further analysis for a variety of inflammatory cytokines, matrix metalloproteinases (MMPs), tissue inhibitors of metalloproteinases (TIMPs) and albumin. Expression of MMPs (MMP-2 and MMP-9) and TIMP isoforms (TIMP-1 and TIMP-2) was assessed using Fluorokine MAP Multiplex Kits (R\&D Systems, Minneapolis, MN, USA) and analyzed on a Luminex 100 analyzer (Luminex 100 System; Luminex, Austin, TX, USA). Interleukin (IL)-5, interferon (IFN)- $\gamma$, IL-17, IL-10, and eosinophil cationic protein (ECP) were measured using the BD Cytometric Bead Array Human Enhanced Sensitivity Flex Set System (BD Biosciences, Biosciences, San Jose, CA, USA), which uses particles with discrete fluorescence intensities to measure the concentration of specific analytes. Albumin and transforming growth factor (TGF)- $\beta$ 
levels in tissue homogenates were determined using commercially available enzyme-linked immunosorbent assay kits (R\&D Systems). When enough samples were not available to undertake all the assessments, samples from fewer patients were assessed for cytokines and cell counts than the total samples from all the patients included in the study.

Fresh polyp tissues were used for the assessment of T helper (Th) 1, Th2, Th17, type 1 regulatory T (TR1; the most important subset of inducible regulatory T (Treg) cells, which secrete IL-10 and TGF- $\beta$ ), and natural regulatory T (nTreg cells; which are thymus-derived and characterized by their $\mathrm{CD} 41^{+} \mathrm{CD} 25^{+} \mathrm{Foxp} 3^{+}$phenotype) by flow cytometric analysis. The polyp tissues were washed and cut into small fragments before teasing apart to allow dispersion of the nasal cells into RPMI 1640 media (Life Technologies, Rockville, MD, USA). The samples dispersed were passed through a $40-\mathrm{mm}$ pore size mesh to obtain a single-cell suspension; after rinsing with fresh RPMI 1640 medium, cells were adjusted to a concentration of $2 \times 10^{6}$ cells $/ \mathrm{mL}$.

T-cell subsets in polyp tissues were phenotyped using the FACSAria Flow Cytometer (BD Biosciences), according to the manufacturer's instructions. We gated on lymphocytes first based on forward scatter and side scatter and then gated on $\mathrm{CD} 4{ }^{+}$cells with anti-CD4allophycocyanin H7 (12 $\mu \mathrm{g} / \mathrm{mL})$, which could be stained only on live cells, excluding dead cells/doublets. Each antibody was matched with a respective isotype $\mathrm{IgG}_{1}$ as a control, and the gating threshold was set accordingly. Cells were labeled with specific mAbs in different combinations as follows: anti-CD25-PerCP CY7 (12 $\mu \mathrm{g} / \mathrm{mL})$, anti-IL-4-Alexa Flour 488 (0.125 $\mathrm{mg} / 5 \mathrm{~mL})$, anti-IL-10-phycoerythrin $(0.03 \mu \mathrm{g} / 20 \mu \mathrm{L})$, anti-IL-17A Alexa Flour 647 (0.25 $\mu \mathrm{g} / 20$ $\mu \mathrm{L})$, anti-IFN- $\gamma$-PerCP-CY5.5 (0.06 $\mu \mathrm{g} / 5 \mu \mathrm{L})$, and Foxp3-Horizon V450 (50 $\mu \mathrm{g} / \mathrm{mL}$; all from BD PharMingen, San Jose, CA, USA). T-cell subsets were selected for detailed phenotypic analysis as follows: 1 ) Th1 cells were IFN- $\gamma^{+} \mathrm{IL}-4^{-} \mathrm{CD} 4^{+} \mathrm{T}$ cells; 2) Th2 cells were IFN- $\gamma^{-}$IL$4^{+} \mathrm{CD} 4^{+} \mathrm{T}$ cells; 3) Th17 cells were IL-17A ${ }^{+} \mathrm{CD} 4^{+} \mathrm{T}$ cells; 4) TR1 cells were IL-10 ${ }^{+} \mathrm{IL}-4^{-} \mathrm{CD} 4^{+} \mathrm{T}$ cells; and 5) nTreg cells were $\mathrm{CD} 4^{+} \mathrm{CD} 25^{+} \mathrm{Foxp}^{+} \mathrm{T}$ cells.

\section{Safety assessment}

Adrenal function was determined on the basis of changes in morning serum cortisol levels. Venous blood samples were obtained no later than $8 \mathrm{a}$.m. when possible, and analyzed by a radioimmunoassay (Dxl 800 Acces Immunoassay system, Beckman Coulter, Indianapolis, IN, USA).

The incidence of adverse events (AEs) experienced by individual patients was also recorded.

\section{Statistical analysis}

The sample size was estimated by power statistics, using the reduction in NP size as the primary outcome measure, as we have described before. ${ }^{2}$ Based on the preliminary findings of a pilot study, we estimated that 30 patients in each group would be sufficient to demonstrate significant differences between the treatments. Statistical analysis was performed with GraphPad Prism software (version 7.00; GraphPad Software, San Diego, CA, USA). Paired or unpaired $t$ tests were used when data were normally distributed, and nonparametric tests were used when data were not normally distributed. The KruskalWallis test was used to compare 3 or more unpaired groups, and a 2-tailed Mann-Whitney test was used when comparing only 2 unpaired groups. The Wilcoxon matched pairs test was used when comparing 2 groups of matched data. A $P$ value of $<0.05$ was considered statistically significant. 


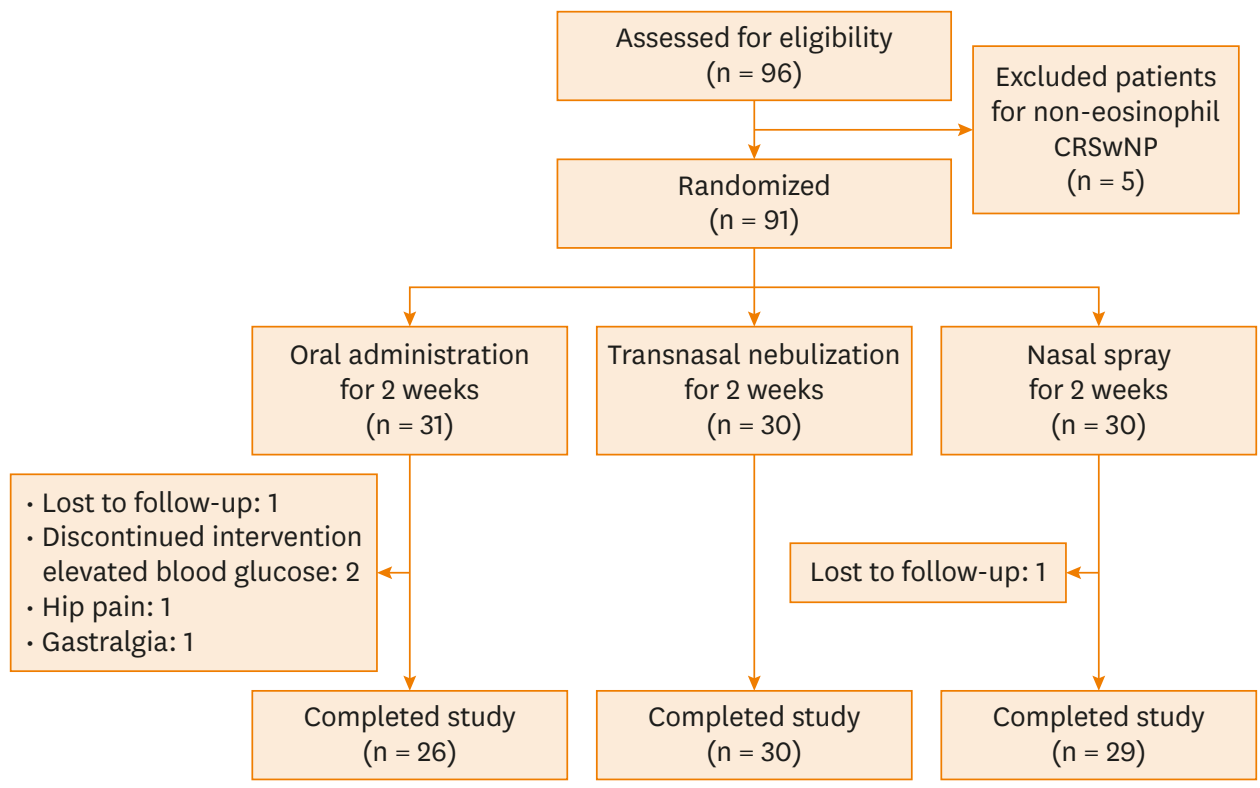

Fig. 1. Flow diagram of patients enrolled in the study. CRSwNP, chronic rhinosinusitis with nasal polyps.

\section{RESULTS}

\section{Patient demographic and baseline characteristics}

A total of 91 patients were randomly allocated to 3 treatment groups: 31 in group A, 30 in group B and 30 in group C. One patient each in groups A and C was lost to follow-up, and 4 patients dropped out due to side effects (Fig. 1).

Of the remaining patients, 46 were male and 38 were female, with a mean age of 43 years (range, 23-64 years). The 3 groups were well matched in demographic characteristics, symptom severity, polyp size and concurrent illness at baseline (Table).

Table. Patient demographic and baseline characteristics

\begin{tabular}{|c|c|c|c|c|}
\hline Characteristics & Group A $(n=26)$ & Group B $(n=30)$ & Group C $(n=28)$ & $P$ value \\
\hline Age $(y r)$, mean (SD) & $43.42(12.22)$ & $42.33(10.40)$ & $43.14(11.00)$ & 0.93 \\
\hline Sex (male/female) & $13 / 13$ & $17 / 13$ & $16 / 12$ & 0.35 \\
\hline Polyp size score, mean (range) & $4.9(4.0-6.0)$ & $4.7(4.0-6.0)$ & $4.8(4.0-6.0)$ & 0.37 \\
\hline Olfactory score, mean (range) & $8.7(6.0-10.0)$ & $8.8(7.8-10.0)$ & $8.4(5.0-10.0)$ & 0.21 \\
\hline Rhinorrhea score, mean (range) & $7.9(4.3-9.3)$ & $7.7(5.0-9.6)$ & $7.5(5.6-9.0)$ & 0.25 \\
\hline Nasal obstruction score, mean (range) & $8.4(7.0-9.5)$ & $8.2(7.5-9.4)$ & $8.2(7.4-9.4)$ & 0.38 \\
\hline Facial pain/Headache score, mean (range) & $3.2(3.5-8.5)$ & $4.9(2.0-7.8)$ & $5.1(2.8-7.8)$ & 0.51 \\
\hline TNSS, mean (range) & $30.3(24.0-34.0)$ & $29.6(26.0-33.2)$ & $29.2(24.9-32.1)$ & 0.06 \\
\hline Asthma (yes/no) & $6 / 20$ & $5 / 25$ & $6 / 22$ & 0.39 \\
\hline Oral FENO, mean (range) & $48.8(10.0-261.0)$ & $46.2(21.0-150.0)$ & $43.1(9.0-120.0)$ & 0.72 \\
\hline Plasma cortisol ( $\mu \mathrm{g} / \mathrm{dL})$, mean $(\mathrm{SD})$ & $18.0(3.1)$ & $17.8(2.8)$ & $17.3(2.1)$ & 0.60 \\
\hline Tissue EOS (\% in the total cell count), mean (range) & $71.3(56.1-90.0)$ & $72.9(59.6-91.5)$ & $73.1(61.2-89.7)$ & 0.73 \\
\hline
\end{tabular}

Group A received oral methylprednisolone $24 \mathrm{mg}$ once a day; group B received $1 \mathrm{mg} / 2 \mathrm{~mL}$ Pulmicort Respules BIS twice daily; and group C received budesonide nasal spray $256 \mu \mathrm{g}$ BID. A $P$ value of less than 0.05 was considered a significant difference. There were no other statistically significant differences between the groups on baseline characteristics.

SD, standard deviation; TNSS, total nasal symptom score; FeNO, fractional nitric oxide; EOS, eosinophil. 


\section{Effect of treatment on clinical outcomes}

At the end of treatment, the 4 major symptoms and TNSS were significantly improved from baseline in groups A and B $(P<0.05$, Fig. 2A-E). Similarly, significant improvements were noted in groups $A$ and $B$ for NP scores (group A: pre-treatment score $4.92 \pm 0.72$, posttreatment score $2.88 \pm 0.59, P<0.001$; group B: pre-treatment score $4.67 \pm 0.66$, posttreatment score $3.33 \pm 0.71, P<0.001$ ) (Fig. 2F) and for FEV1/FVC (group A: pre-treatment $76.86 \pm 2.93$, post-treatment $90.68 \pm 5.53, P=0.002$; group B, pre-treatment $80.15 \pm 3.56$,
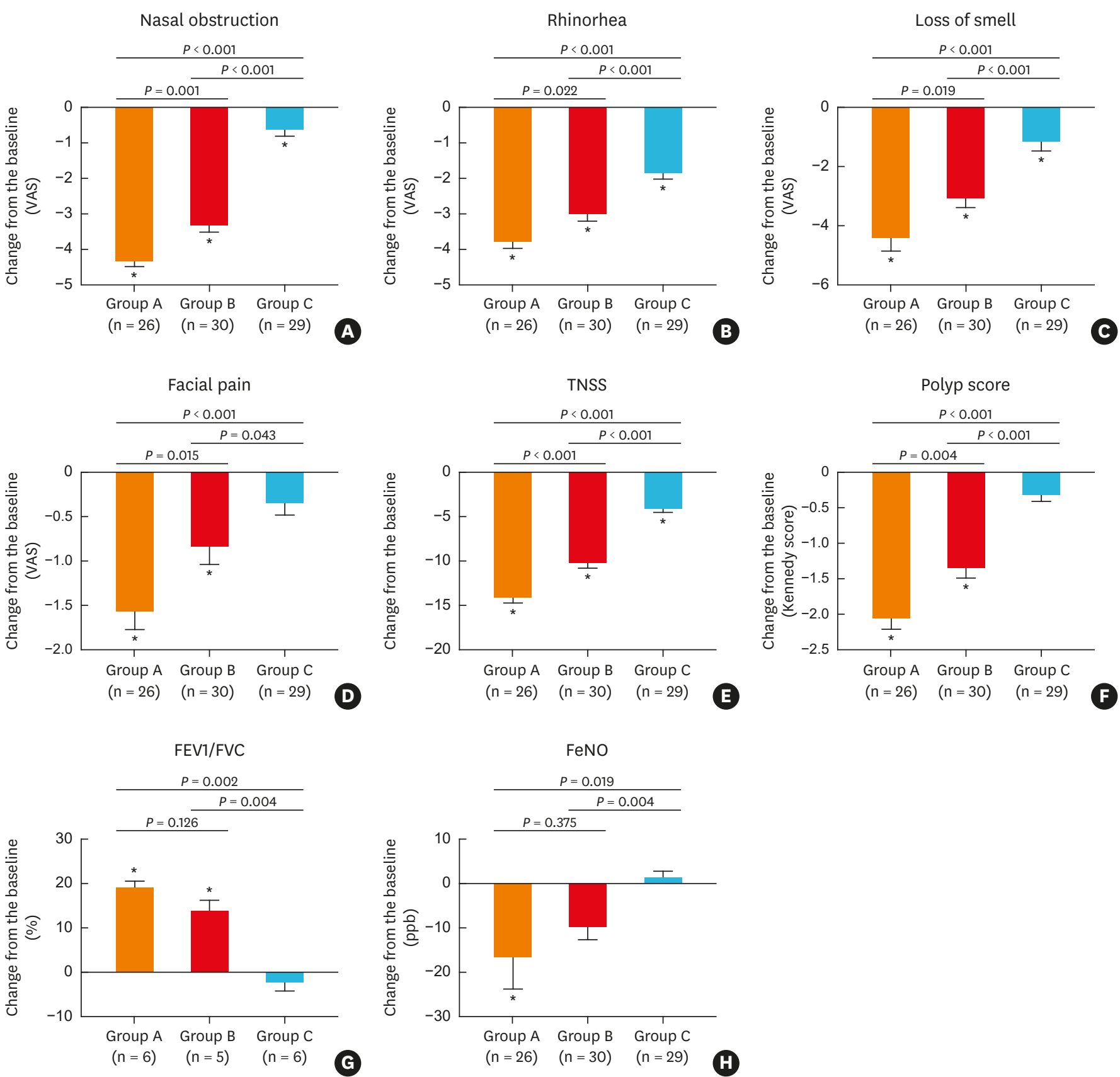

Fig. 2. Effect of different treatments on clinical outcomes as primary end points: (A) nasal obstruction, (B) rhinorhea, (C) loss of smell, (D) facial pain, (E) TNSS, (F) polyp score, (G) FEV1/FVC, (H) FeNO.

VAS, visual analogue scale TNSS, total nasal symptom score; FEV1, forced expiratory volume in 1 second; FVC, forced vital capacity; FeNO, fractional nitric oxide. ${ }^{*} P<0.05$ compared to baseline (before treatment). 
post-treatment $98.97 \pm 3.86, P=0.008$ ) (Fig. 2G). However, FeNO was significantly decreased in group A $(P=0.048)$, but not in group $\mathrm{B}(P=0.068)$. Moreover, along with improvements in symptoms, the Kennedy scores were also significantly reduced by $28.5 \%$ in group B. A similar trend toward improvement in major symptoms was demonstrated in group C, except for facial pain; however, there was no significant improvement in the NP score $(P=0.054$, Fig. $\mathbf{2 F})$, FEV1/FVC $(P=0.550$, Fig. 2 G) or FeNO $(P=0.780$, Fig. 2 H $)$. The level of improvement for each clinical outcome was similar between groups A and B; however, it was greater in groups A and $\mathrm{B}$ than in group C.

\section{Effect of treatment on inflammatory cytokines, mediators and cellular infiltration}

Assessment of NP tissue samples for the effects of treatment on inflammatory cytokines, remodeling markers or T-cell subsets demonstrated that oral methylprednisolone (group A) and BIS via transnasal nebulization (group B) significantly reduced ECP (Fig. 3A) and IL-5 (Fig. 3C) levels and significantly increased IL-10 (Fig. 3D) levels in NPs compared with baseline values. TGF- $\beta$ was also significant increased from baseline by oral methylprednisolone only

(Fig. 3F). In contrast, IL-17 (Fig. 3E) and IFN- $\gamma$ (Fig. 3B) levels were not significantly altered by oral methylprednisolone or BIS treatment. Similarly, budesonide aqueous nasal spray (group C) did not alter the level of any of these cytokines, compared to baseline values, apart from
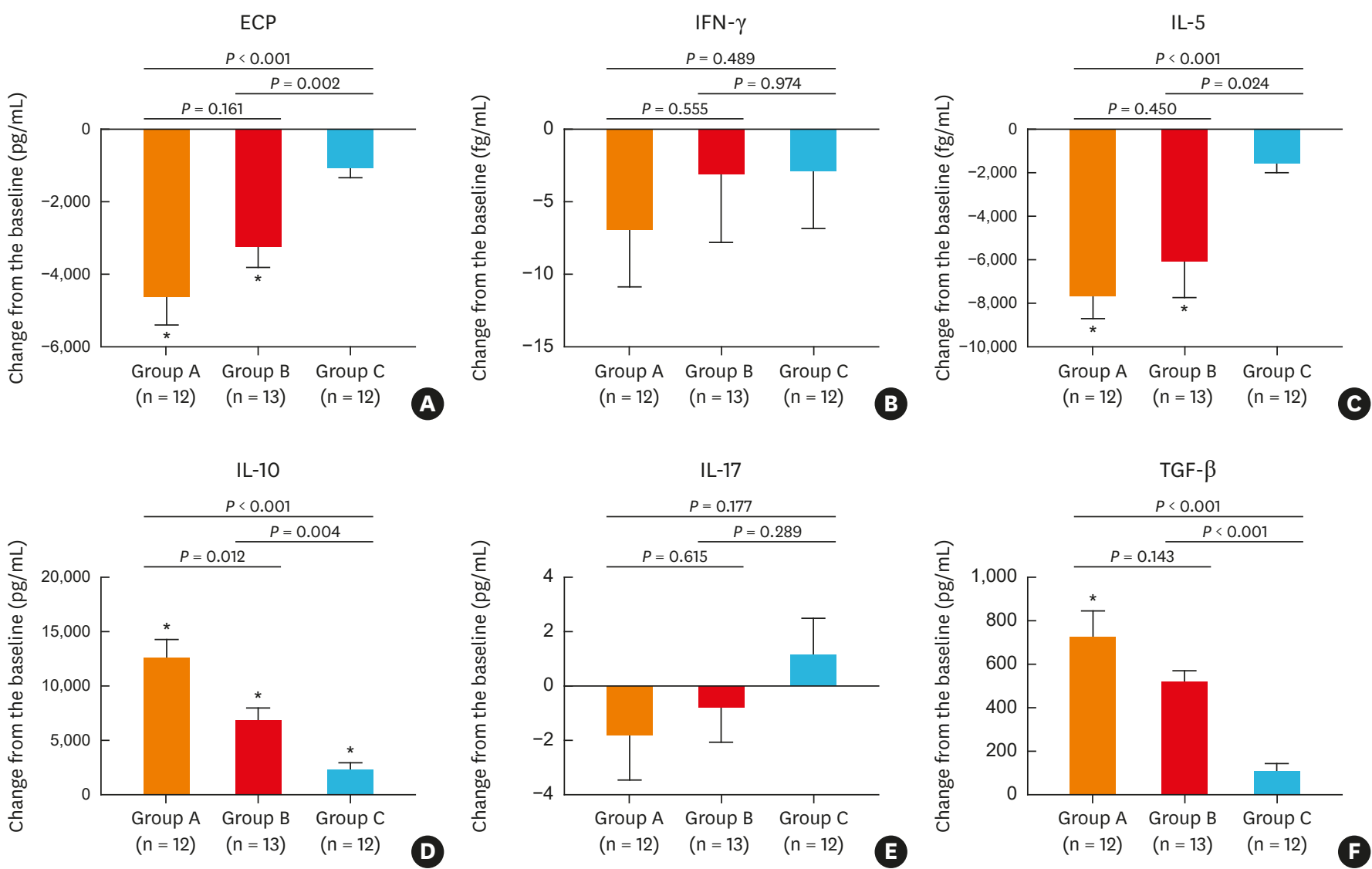

Fig. 3. Effect of different treatments on inflammatory cytokines and mediators in tissue homogenates: (A) ECP, (B) IFN- $\gamma$, (C) IL-5, (D) IL-10, (E) IL-17, (F) TGF- $\beta$. ECP, IL-5, IL-10, IL-17, and IFN- $\gamma$ were determined using cytometric bead array, and TGF- $\beta$ using enzyme-linked immunosorbent assay. ECP, eosinophil cationic protein; IFN- $\gamma$, interferon- $\gamma$; IL, interleukin; TGF- $\beta$, transforming growth factor- $\beta$. ${ }^{*} P<0.05$ compared to baseline (before treatment). 

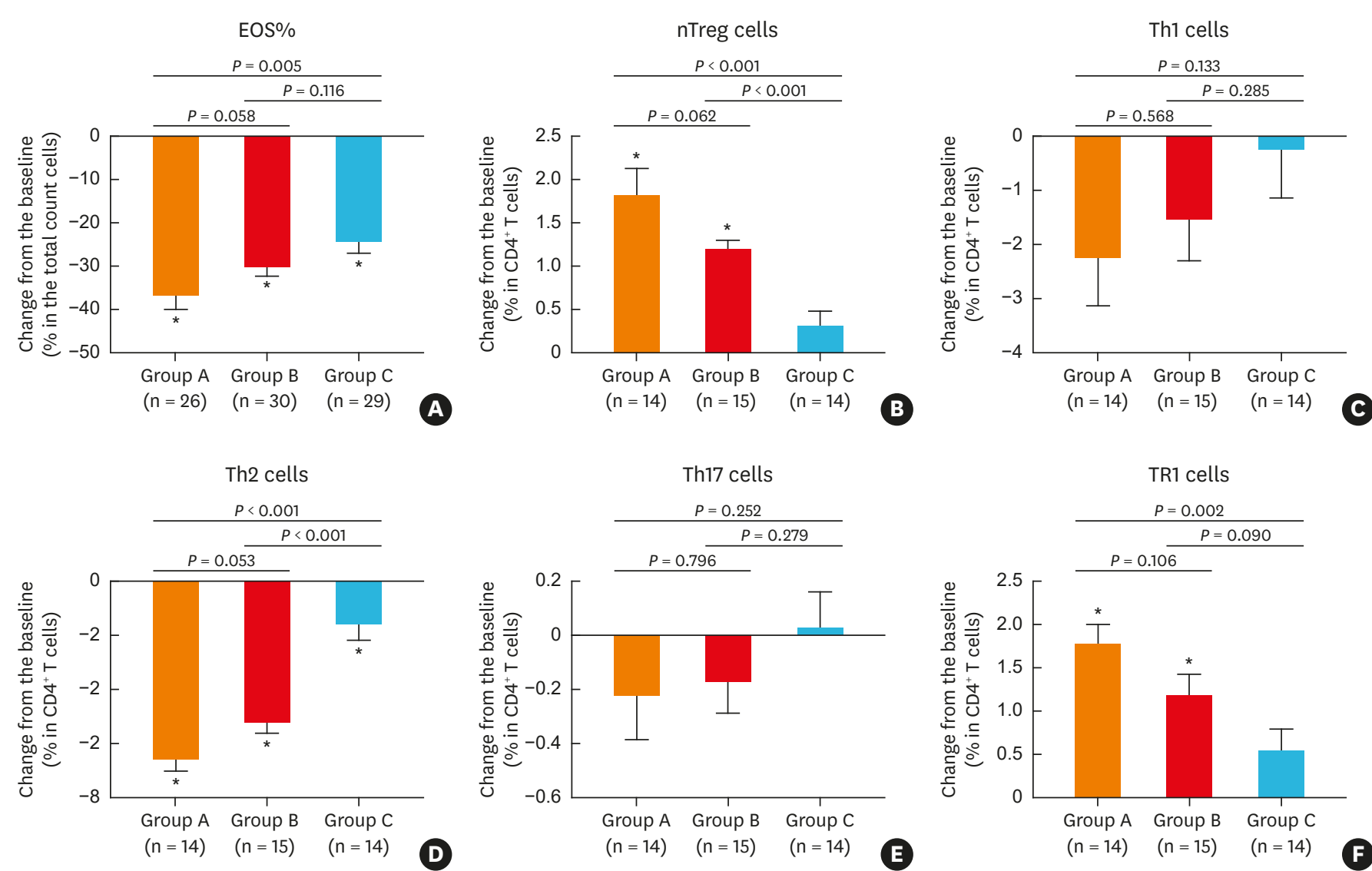

Fig. 4. Effect of different treatments on inflammatory cells in nasal polyp tissue: (A) percentage of tissue eosinophils in the total cell count, (B) nTreg cells, (C) Th1 cells, (D) Th2 cells, (E) Th17 cells, (F) TR1 cells. Eosinophils were determined using hematoxylin and eosin staining and T-cell subsets using flow cytometric analysis. EOS, eosinophil; nTreg, natural regulatory $\mathrm{T}$; Th, $\mathrm{T}$ helper.

${ }^{*} P<0.05$ compared to baseline (before treatment).

IL-10, which was significantly increased ( $P=0.009$, Fig. 3D). The improvements from baseline levels for ECP (Fig. 3A), IL-5 (Fig. 3C), IL-10 (Fig. 3D), and TGF- $\beta$ (Fig. 3F) were greater in both groups $\mathrm{A}$ and $\mathrm{B}$, compared to group $\mathrm{C}$. Moreover, the change from baseline in these outcomes was also greater in group $\mathrm{A}$ than in group B.

In line with the cytokine patterns observed, the inflammatory cells in NPs showed similar proportions of eosinophils at baseline in all enrolled patients, and the percentage of tissue eosinophils in the total cell count were significantly reduced following treatment in all 3 groups (Fig. 4A). Similarly, the number of Th2 cells in NPs was significantly decreased after treatment in the 3 groups, compared to baseline (Fig. 4D), whereas the those of Th1 (Fig. 4C) and Th17

(Fig. 4E) cells were not affected by any treatment. Interestingly, BIS transnasal nebulization and oral methylprednisolone also significantly increased the numbers of TR1 (Fig. 4F) and nTreg

(Fig. 4B) cells from baseline levels. While changes in the numbers of Th2 (Fig. 4D) and nTreg (Fig. 4B) cells was greater in groups A and B compared to group C, those of Th1 (Fig. 4C) and Th17 (Fig. 4E) cells was comparable among the 3 groups. Moreover, there was a significant difference in changes in eosinophil (Fig. 4A) and TR1 (Fig. 4F) cells between groups A and C.

\section{Tissue remodeling as a secondary outcome}

Assessment of collagen deposition in the extracellular matrix of NP tissues demonstrated that the total collagen amount was increased in polyp samples with all 3 treatments 

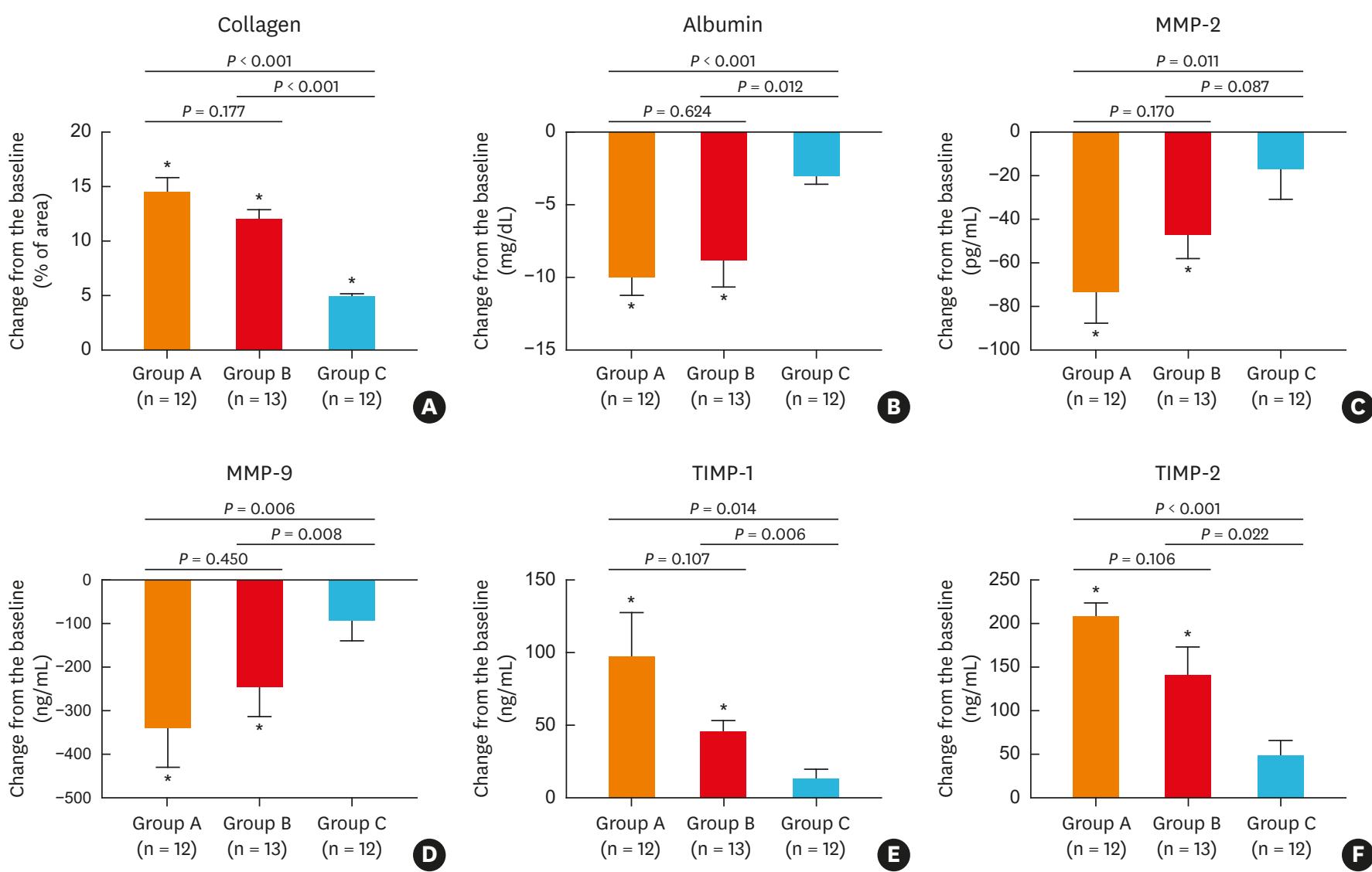

Fig. 5. Remodeling pattern shifts in nasal polyp tissues following different treatments: (A) collagen, (B) albumin, (C) MMP-2, (D) MMP-9, (E) TIMP-1, (F) TIMP-2. MMP, matrix metalloproteinase; TIMP, tissue inhibitors of metalloproteinase.

${ }^{*} P<0.05$ compared to baseline (before treatment). 


\section{DISCUSSION}

This is the first randomized and head-to-head study to quantify the relative effectiveness and safety of corticosteroids administered by 3 different administration routes, namely, BIS via intranasal nebulization, BNS and oral methylprednisolone, in patients with ECRSwNP. Although it is not appropriate to compare the efficacy of systemic and topical steroid administration over a short period of 2 weeks, particularly as the maximum time course for benefit differs between systemic and topical steroids, the objective of this study was to evaluate differences among the short-term therapies, rather than differences in the maximum benefits of the 3 therapies. Therefore, the present study provides an opportunity to gain greater insight into the route of steroid administration, which delivers the best balance between efficacy and safety, and further evaluates the short-term application of BIS during the perioperative period in patients with ECRSwNP. In this respect, the present study has demonstrated that treatment for 2 weeks with BIS via nebulization significantly improved the major nasal symptoms and reduced polyp size, which were not as marked after treatment with BNS. Moreover, in patients with comorbid asthma, BIS via nebulization was also effective in asthma control as evidenced by improvement in FEV1/FVC and reduced levels of FeNO, similar to that demonstrated by oral methylprednisolone. Indeed, BIS and oral methylprednisolone were both superior to BNS in this respect. Additionally, local immunological markers, including eosinophil numbers, Th2 cells and ECP, were decreased to the greatest extent in the NP tissues of patients treated with oral methylprednisolone, followed by patients administered BIS. Moreover, oral methylprednisolone and BIS also led to significant improvements in a variety of markers of tissue remodeling; thus, highlighting the potential mechanisms underlying the clinical effects of these treatments.

Safety of BIS nebulization was verified by the results of no significant reduction in serum cortisol level or incidence of any serious AEs during treatment, similar to that noted for BNS. In contrast, oral methylprednisolone led to significant reduction in serum cortisol levels and incidence of AEs, which led several patients to drop out of the study.

The findings of the current study on the efficacy of the treatments in attenuating symptoms of CRSwNP are generally in accordance with those of previously published studies. Current international guidelines recommend corticosteroids therapy as the core of medical treatment for chronic rhinosinusitis with NPs. ${ }^{2,15,17}$ Indeed, several studies support the use of systemic corticosteroids for NP either as primary therapy or before/after endoscopic sinus surgery. ${ }^{18-22}$ The finding of reduction in polyp size after 2-week treatment in the present study is also in accordance with those of other studies, which have demonstrated a dramatic reduction in polyp size within 2 weeks. ${ }^{17,19}$ Nevertheless, the potent efficacy of an oral steroid must be weighed against the potential AEs, such as residual adrenal suppression ${ }^{20}$ or reduction in osteoblast activity. ${ }^{7}$ Although there is an abundance of literature acknowledging the efficacy of corticosteroids applied topically by nasal sprays in reducing polyp size and improving symptoms $\mathrm{s}^{23-28}$ as well as demonstrating relatively high safety in their use; an initially large volume of the NP does not allow a rapid and significant effect of the topical therapy over a short course of treatment. Thus, prolonged use is necessary for eliciting the maximal effect of intranasal corticoid spray in CRSwNP. ${ }^{20,23}$

Although BIS nebulization has not been reported as a routine preoperative treatment of ECRSwNP, the off-label use of BIS in nasal irrigation or nebulization has been reported for the management of CRSwNP. ${ }^{911}$ In accordance with these studies, the current study has also 
demonstrated that short-term use of BIS nebulization is effective in delivering significant improvements in nasal symptoms and polyp size. The significant reduction in nasal obstruction and loss of smell scores may partly result from decreases in angiogenesis, blood flow and capillary bed permeability. ${ }^{29,30}$

The efficacy of glucocorticoids is primarily related to the effective dose, type and route of delivery, which determine their bioavailability. In this respect, the efficacy of the 2 topical steroid preparations, BIS and BNS investigated in the current study is likely to be affected by the amount and distribution of the initial dose deposited in the nasal cavity. ${ }^{31}$ Although the amount of BIS deposited in the nasal mucosa is greater with nasal sprays than by nebulization ( $2 \mathrm{mg} v \mathrm{~s}$. $512 \mu \mathrm{g}$ daily), nebulization provides a more widespread distribution of the intranasal steroid and increases the volume of delivery with relatively higher quantities of steroid than the nasal spray. ${ }^{32}$ Indeed, it has been estimated that a 1-minute pulsating aerosol delivery can deposit comparable amounts to 2 puffs of a nasal pump spray in the nasal cavity, and $10-15 \mathrm{~mL}$ of the nebulized solution to the sinus. ${ }^{33}$ Moreover, continuous delivery of BIS by nebulization reduces mucus ciliary system clearance and increases the volume of topical absorption. Furthermore, the fine-particle $(5-10 \mu \mathrm{m})$ dose of BIS is more suitable for mucosa absorption..$^{33}$

Our study also evaluated the local anti-inflammatory effects of steroids on NPs as well as the systemic effects. As NPs in the 3 groups were characterized by inflammation dominated by eosinophilic infiltration, the observation that there was a significant reduction in eosinophil and Th2 cell numbers in the local tissue after treatment with BIS supports the evidence for the anti-inflammatory potential of BIS. Of the Th2 cytokines, IL- 5 has been shown to be important for eosinophil differentiation, and also activates and enhances the survival of these cells, ${ }^{34}$ while IL-10 and TGF- $\beta$ are intrinsic anti-inflammatory cytokines. In this respect, our finding that oral and topical steroids significantly reduced ECP and IL-5, and increased IL-10 levels in nasal secretions of ECRSwNP patients is in accordance with those of others studies. ${ }^{35,36}$ Specifically, IL-10 is of particular interest because it is instrumental in TR1-mediated suppression of proliferation and cytokine production by Th1 and Th2 cells, and activation of T cells in the presence of IL-10 induces a long-lasting state of nonresponsiveness or anergy. ${ }^{37}$ Furthermore, TGF- $\beta$ can induce IL-10, and IL-10 facilitates TGF- $\beta$ regulatory activity. ${ }^{38}$ In this regard, the finding that TGF- $\beta$ promotes Treg cells in vitr $0^{39}$ is also in accordance within that of ours.

Indeed, TGF- $\beta$ and Treg cell function has also been shown to be involved in tissue remodeling of ECRSwNP, which is characterized by extracellular matrix degradation caused by low levels of TGF- $\beta$, lack of Treg function and increased MMP activity with low levels of tissue TIMP. ${ }^{40}$ In this regard, our findings that the expression of MMP-2 and MMP-9 was significantly decreased and concentrations of TIMP-1 and that TIMP-2 was significantly increased following treatment with BIS and oral methylprednisolone are also in accordance with those of other studies. ${ }^{41}$

Consistent with previous studies investigating the use of BIS nebulization in asthmatics, ${ }^{42-44}$ the current study also showed no effect of treatment on hypothalamic-pituitary-adrenal (HPA) axis suppression as evidenced by lack of significant changes in morning serum cortisol over the treatment period. Serum cortisol levels of the treated patients did not differ from the reference values of the laboratory; however, serum cortisol was reduced by $18.7 \%$ in the BIS-treated group, $2.2 \%$ in the nasal spray-treated group and $87.9 \%$ in the oral methylprednisolone-treated group. The small reduction in serum cortisol noted in BIS-treated patients was primarily an adaption to exogenous corticosteroid, but not considered as a clinically relevant AE because 
neither symptoms nor signs were detected. The lack of apparent effect on the HPA axis during BIS treatment thus exemplifies the negligible systemic side effect and indicates that BIS is safer and more efficacious than oral prednisolone over a 2-week treatment period for the management of patients with ECRSwNP. Thus, it is tempting to recommend $1 \mathrm{mg} / 2 \mathrm{~mL}$ Pulmicort Respules BIS twice daily for 2 weeks as a useful treatment option in the management of patients with ECRSwNP. However, these findings need to be confirmed in future studies involving larger numbers of patients of different ethnicities. Subsequent assessment of the magnitude of the response and any corresponding AEs should also be performed to evaluate the dose-dependent effects of BIS after treatment. In addition, despite having several advantages, some drawbacks of a nebulizer, such as loud noise, lower portability than inhalers, more timeconsuming administration of drugs, and lower efficiency as they require an electric source for operation, may possibly affect compliance. Thus, future studies should also take into account compliance in view of these features of nebulization.

This study is somewhat limited in that we estimated the extent of endogenous adrenocortical activity by measuring morning plasma cortical levels. This test only provides a momentary value and may be affected by the dynamic circadian rhythm of plasma adrenocorticotrophic hormone. Indeed, wide inter-subject and intra-subject variations in measurements suggest that the test has low sensitivity for detecting adrenal insufficiency.

In conclusion, the results of this study indicate that twice daily administration of $1 \mathrm{mg} / 2$ $\mathrm{mL}$ BIS nebulization is an efficacious treatment for ECRSwNP, particularly as it provides significant relief of symptoms, reduction in polyp size, and overall control of mucosal inflammation and tissue remodeling. In this regard, BIS treatment also provides better clinical efficacy than BNS. Although it is possible that BIS may affect the lower airways, overall this treatment option is relatively safe as it neither significantly alters plasma cortisol levels nor elicits any severe AEs over a period of 2 weeks. Thus, we suggest that short-term BIS via transnasal nebulization may be useful as a routine adjunct in the management of ECRSwNP, especially for severe ECRSwNP patients into whom oral steroids may be contraindicated.

\section{ACKNOWLEDGMENTS}

This work was supported by grants from National Key R \& D Program of China (2018YFC0116800, 2016YFC20160905200), the national natural science foundation of China (81630023, 81420108009, 81400444 and 81470678), the Program for Changjiang Scholars and Innovative Research Team (IRT13082), the Capital Health Development Foundation (2016-12052), Beijing Municipal Administration of Hospitals' Mission Plan (SML20150203), Beijing Municipal Administration of Hospitals' Youth Programme (QML20150202), Capital Health Development Foundation (2016-1-2052) and Beijing Advanced Innovation Center for Food Nutrition and Human Health (Beijing Technology and Business University [BTBU] 20181045).

\section{REFERENCES}

1. Shi JB, Fu QL, Zhang H, Cheng L, Wang YJ, Zhu DD, et al. Epidemiology of chronic rhinosinusitis: results from a cross-sectional survey in seven Chinese cities. Allergy 2015;70:533-9.

PUBMED | CROSSREF 
2. Fokkens WJ, Lund VJ, Mullol J, Bachert C, Alobid I, Baroody F, et al. EPOS 2012: European position paper on rhinosinusitis and nasal polyps 2012. A summary for otorhinolaryngologists. Rhinology 2012;50:1-12. PUBMED | CROSSREF

3. Small CB, Stryszak P, Danzig M, Damiano A. Onset of symptomatic effect of mometasone furoate nasal spray in the treatment of nasal polyposis. J Allergy Clin Immunol 2008;121:928-32. PUBMED | CROSSREF

4. Lund VJ, Black JH, Szabó LZ, Schrewelius C, Akerlund A. Efficacy and tolerability of budesonide aqueous nasal spray in chronic rhinosinusitis patients. Rhinology 2004;42:57-62. PUBMED

5. Vargas R, Dockhorn RJ, Findlay SR, Korenblat PE, Field EA, Kral KM. Effect of fluticasone propionate aqueous nasal spray versus oral prednisone on the hypothalamic-pituitary-adrenal axis. J Allergy Clin Immunol 1998;102:191-7.

PUBMED | CROSSREF

6. Mullol J, Obando A, Pujols L, Alobid I. Corticosteroid treatment in chronic rhinosinusitis: the possibilities and the limits. Immunol Allergy Clin North Am 2009;29:657-68. PUBMED | CROSSREF

7. Winblad L, Larsen CG, Håkansson K, Abrahamsen B, von Buchwald C. The risk of osteoporosis in oral steroid treatment for nasal polyposis: a systematic review. Rhinology 2017;55:195-201. PUBMED | CROSSREF

8. Rajasekaran K, Seth R, Abelson A, Batra PS. Prevalence of metabolic bone disease among chronic rhinosinusitis patients treated with oral glucocorticoids. Am J Rhinol Allergy 2010;24:215-9. PUBMED | CROSSREF

9. Bhalla RK, Payton K, Wright ED. Safety of budesonide in saline sinonasal irrigations in the management of chronic rhinosinusitis with polyposis: lack of significant adrenal suppression. J Otolaryngol Head Neck Surg 2008;37:821-5. PUBMED

10. Welch KC, Thaler ER, Doghramji LL, Palmer JN, Chiu AG. The effects of serum and urinary cortisol levels of topical intranasal irrigations with budesonide added to saline in patients with recurrent polyposis after endoscopic sinus surgery. Am J Rhinol Allergy 2010;24:26-8. PUBMED | CROSSREF

11. Lavigne F, Cameron L, Renzi PM, Planet JF, Christodoulopoulos P, Lamkioued B, et al. Intrasinus administration of topical budesonide to allergic patients with chronic rhinosinusitis following surgery. Laryngoscope 2002;112:858-64. PUBMED | CROSSREF

12. Thamboo A, Manji J, Szeitz A, Santos RD, Hathorn I, Gan EC, et al. The safety and efficacy of short-term budesonide delivered via mucosal atomization device for chronic rhinosinusitis without nasal polyposis. Int Forum Allergy Rhinol 2014;4:397-402. PUBMED | CROSSREF

13. Wang C, Lou H, Wang X, Wang Y, Fan E, Li Y, et al. Effect of budesonide transnasal nebulization in patients with eosinophilic chronic rhinosinusitis with nasal polyps. J Allergy Clin Immunol 2015;135:922-929.e6. PUBMED | CROSSREF

14. Lou H, Meng Y, Piao Y, Zhang N, Bachert C, Wang C, et al. Cellular phenotyping of chronic rhinosinusitis with nasal polyps. Rhinology 2016;54:150-9. PUBMED | CROSSREF

15. Scadding GK, Durham SR, Mirakian R, Jones NS, Drake-Lee AB, Ryan D, et al. BSACI guidelines for the management of rhinosinusitis and nasal polyposis. Clin Exp Allergy 2008;38:260-75. PUBMED | CROSSREF

16. Li X, Meng J, Qiao X, Liu Y, Liu F, Zhang N, et al. Expression of TGF, matrix metalloproteinases, and tissue inhibitors in Chinese chronic rhinosinusitis. J Allergy Clin Immunol 2010;125:1061-8. PUBMED | CROSSREF

17. Ecevit MC, Erdag TK, Dogan E, Sutay S. Effect of steroids for nasal polyposis surgery: a placebocontrolled, randomized, double-blind study. Laryngoscope 2015;125:2041-5. PUBMED | CROSSREF

18. Pundir V, Pundir J, Lancaster G, Baer S, Kirkland P, Cornet M, et al. Role of corticosteroids in functional endoscopic sinus surgery--a systematic review and meta-analysis. Rhinology 2016;54:3-19. PUBMED | CROSSREF

19. Hissaria P, Smith W, Wormald PJ, Taylor J, Vadas M, Gillis D, et al. Short course of systemic corticosteroids in sinonasal polyposis: a double-blind, randomized, placebo-controlled trial with evaluation of outcome measures. J Allergy Clin Immunol 2006;118:128-33.

PUBMED | CROSSREF 
20. Vaidyanathan S, Barnes M, Williamson P, Hopkinson P, Donnan PT, Lipworth B. Treatment of chronic rhinosinusitis with nasal polyposis with oral steroids followed by topical steroids: a randomized trial. Ann Intern Med 2011;154:293-302. PUBMED | CROSSREF

21. Damm M, Jungehülsing M, Eckel HE, Schmidt M, Theissen P. Effects of systemic steroid treatment in chronic polypoid rhinosinusitis evaluated with magnetic resonance imaging. Otolaryngol Head Neck Surg 1999;120:517-23. PUBMED | CROSSREF

22. Bonfils P, Norès JM, Halimi P, Avan P. Corticosteroid treatment in nasal polyposis with a three-year follow-up period. Laryngoscope 2003;113:683-7. PUBMED | CROSSREF

23. Jankowski R, Schrewelius C, Bonfils P, Saban Y, Gilain L, Prades JM, et al. Efficacy and tolerability of budesonide aqueous nasal spray treatment in patients with nasal polyps. Arch Otolaryngol Head Neck Surg 2001;127:447-52. PUBMED | CROSSREF

24. Zhou B, He G, Liang J, Cheng L, Mehta A, Liu S, et al. Mometasone furoate nasal spray in the treatment of nasal polyposis in Chinese patients: a double-blind, randomized, placebo-controlled trial. Int Forum Allergy Rhinol 2016;6:88-94.

PUBMED | CROSSREF

25. Chur V, Small CB, Stryszak P, Teper A. Safety of mometasone furoate nasal spray in the treatment of nasal polyps in children. Pediatr Allergy Immunol 2013;24:33-8. PUBMED | CROSSREF

26. Stjärne P, Blomgren K, Cayé-Thomasen P, Salo S, Søderstrøm T. The efficacy and safety of once-daily mometasone furoate nasal spray in nasal polyposis: a randomized, double-blind, placebo-controlled study. Acta Otolaryngol 2006;126:606-12. PUBMED | CROSSREF

27. Stjärne P, Mösges R, Jorissen M, Passàli D, Bellussi L, Staudinger H, et al. A randomized controlled trial of mometasone furoate nasal spray for the treatment of nasal polyposis. Arch Otolaryngol Head Neck Surg 2006;132:179-85. PUBMED | CROSSREF

28. Small CB, Hernandez J, Reyes A, Schenkel E, Damiano A, Stryszak P, et al. Efficacy and safety of mometasone furoate nasal spray in nasal polyposis. J Allergy Clin Immunol 2005;116:1275-81. PUBMED | CROSSREF

29. Bellodi S, Tosca MA, Pulvirenti G, Petecchia L, Serpero L, Silvestri M, et al. Activity of budesonide on nasal neutrophilic inflammation and obstruction in children with recurrent upper airway infections. A preliminary investigation. Int J Pediatr Otorhinolaryngol 2006;70:445-52. PUBMED | CROSSREF

30. Holmberg K, Bake B, Pipkorn U. Nasal mucosal blood flow after intranasal allergen challenge. J Allergy Clin Immunol 1988;81:541-7. PUBMED | CROSSREF

31. Labiris NR, Dolovich MB. Pulmonary drug delivery. Part I: physiological factors affecting therapeutic effectiveness of aerosolized medications. Br J Clin Pharmacol 2003;56:588-99. PUBMED | CROSSREF

32. Kundoor V, Dalby RN. Assessment of nasal spray deposition pattern in a silicone human nose model using a color-based method. Pharm Res 2010;27:30-6. PUBMED | CROSSREF

33. Möller W, Schuschnig U, Bartenstein P, Meyer G, Häussinger K, Schmid O, et al. Drug delivery to paranasal sinuses using pulsating aerosols. J Aerosol Med Pulm Drug Deliv 2014;27:255-63. PUBMED | CROSSREF

34. Bolard F, Gosset P, Lamblin C, Bergoin C, Tonnel AB, Wallaert B. Cell and cytokine profiles in nasal secretions from patients with nasal polyposis: effects of topical steroids and surgical treatment. Allergy 2001;56:333-8. PUBMED | CROSSREF

35. Van Zele T, Gevaert P, Holtappels G, Beule A, Wormald PJ, Mayr S, et al. Oral steroids and doxycycline: two different approaches to treat nasal polyps. J Allergy Clin Immunol 2010;125:1069-1076.e4. PUBMED | CROSSREF

36. Bachert C, Wagenmann M, Rudack C, Höpken K, Hillebrandt M, Wang D, et al. The role of cytokines in infectious sinusitis and nasal polyposis. Allergy 1998;53:2-13.

PUBMED | CROSSREF 
37. Groux H, Bigler M, de Vries JE, Roncarolo MG. Interleukin-10 induces a long-term antigen-specific anergic state in human CD4+ T cells. J Exp Med 1996;184:19-29. PUBMED | CROSSREF

38. Wan YY, Flavell RA. Regulatory T cells, transforming growth factor-beta, and immune suppression. Proc Am Thorac Soc 2007;4:271-6.

PUBMED | CROSSREF

39. Bettelli E, Carrier Y, Gao W, Korn T, Strom TB, Oukka M, et al. Reciprocal developmental pathways for the generation of pathogenic effector TH17 and regulatory T cells. Nature 2006;441:235-8. PUBMED | CROSSREF

40. Shi LL, Xiong P, Zhang L, Cao PP, Liao B, Lu X, et al. Features of airway remodeling in different types of Chinese chronic rhinosinusitis are associated with inflammation patterns. Allergy 2013;68:101-9. PUBMED | CROSSREF

41. de Borja Callejas F, Martínez-Antón A, Picado C, Alobid I, Pujols L, Valero A, et al. Corticosteroid treatment regulates mucosal remodeling in chronic rhinosinusitis with nasal polyps. Laryngoscope 2015;125:E158-67.

PUBMED | CROSSREF

42. Price DB, Gefen E, Gopalan G, Miglio C, McDonald R, Thomas V, et al. Real-life effectiveness and safety of the inhalation suspension budesonide comparator vs the originator product for the treatment of patients with asthma: a historical cohort study using a US health claims database. Pragmat Obs Res 2017;8:69-83. PUBMED | CROSSREF

43. Lin J, Chen P, Liu C, Kang J, Xiao W, Chen Z, et al. Comparison of fluticasone propionate with budesonide administered via nebulizer: a randomized controlled trial in patients with severe persistent asthma. J Thorac Dis 2017;9:372-85. PUBMED | CROSSREF

44. Tezuka J, Motomura C, Ikei J, Ide K, Kando N, Goto M, et al. Efficacy and safety of budesonide inhalation suspension nebulization by mesh nebulizer in Japanese infants and young children with bronchial asthma in 12-week, randomised, open study. Arerugi 2008;57:1034-42.

PUBMED 